intra-uterine pregnancy of 19 weeks gestation. All along the size of the uterus was bigger than the period of amenorrhoea suggested. The foetal movements were first felt in the second week of January 1971 at 18 weeks gestation (uterine size 22 weeks). She developed mild hypertension on 2 April 1971 and was admitted for rest. An X-ray of the abdomen then revealed a twin pregnancy. The following day she fell down and twisted her left knee and developed a painful haematoma. No fracture was detected. A diagnosis of torn, left semi-lunar cartilage was made and plaster of Paris was applied to be removed in labour. She made a good recovery and went into spontaneous labour on 18 April 1971, and had an uneventful delivery of twin male babies, weighing $2.32 \mathrm{~kg}$ and $2.5 \mathrm{~kg}$. Her second baby was an assisted breech delivery with binovular placenta. Both babies were healthy, and survived.

\section{Discussion}

The case is interesting in that the patient originally had a triplet pregnancy of which one ovum was in an ectopic implantation. We have been able to trace only eight previously recorded cases in the literature with simultaneous intra-uterine and ectopic triplet gestations. The case is also unusual in this series of eight, in that here the ectopic pregnancy appears to have been in the ovary which in itself is a rare site. The findings at laparotomy and histology confirm this. The criteria for ovarian pregnancy (attributed to Spiegelberg, as quoted by Jeffcoate) apply to this case; that is, (i) normal fallopian tube and fimbria, separate from the pregnancy sac, (ii) pregnancy sac in the position of the ovary, and (iii) histological confirmation of the ovarian tissue around the pregnancy.

\section{Acknowledgment}

I am grateful to Dr E. E. Rawlings for permission to publish this case under his care.

\section{References}

Armitage, G.L., Armitage, H.V. \& Chester, P.A. (1955) Combined intra and extrauterine pregnancy; a case report. American Journal of Obstetrics and Gynaecology, 69, 885.

KAPSINOW, R. (1951) Multiple simultaneous unilateral tubal pregnancy. New Orleans Medical and Surgical Journal, 101 (6), 232.

Marshall, G.B. (1903) Case of ruptured tubal gestation associated with twin pregnancy in uterus. Journal of Obstetrics and Gynaecology of the British Commonwealth, 4, 448.

Novak, E. (1926) Combined intrauterine and extra-uterine pregnancy; with a report of 276 cases, including two new cases observed by the author. Surgery, Gynaecology and Obstetrics, 43, 26.

Payne, S., Duge, J. \& Bradbury, W. (1971) Ectopic pregnancy concomitant with twin intra-uterine pregnancy. A case report. Obstetrics and Gynaecology, 38, 905.

VASILJEVIC, V. (1959) Simultaneous intrauterine and bilatera tubal pregnancy. Meditsinski pregled, 12 (5), 300.

YAKIMENKo, A.F. (1963) Combination of normal and bilateral fallopian pregnancy. Akusherstoli Ginekologiya, 3, 126.

Zabaleta Lombana, A. \& Nilanes Pernett, J. (1964) Conjugate triple pregnancy-superfetation. Revista colombiana de obstetricia y ginecologia, 15, 73.

\title{
Tic convulsif: The association of trigeminal neuralgia and hemifacial spasm
}

\author{
R. S. Maurice-Williams \\ F.R.C.S., M.R.C.P. \\ Neurosurgical Registrar, Neurosurgical Unit of Guy's, Maudsley, and King's College Hospitals, \\ De Crespigny Park, London, S.E.5
}

\section{Summary}

Both trigeminal neuralgia and hemifacial spasm are sometimes caused by a posterior fossa mass lesion. When these two disorders co-exist, a rare association known as 'tic convulsif', a lesion involving the fifth and seventh cranial nerves in the cerebellopontine angle is extremely likely. Twenty-eight cases of tic convulsif have been mentioned in the literature and two more case are reported here. They are of interest in that both cases many years elapsed between specialist opinion being first sought and the discovery of the underlying lesion.

\section{Case 1}

In 1960, a 39-year-old housewife developed clumsiness of the right hand and intermittent right facial twitching which had begun round the right eye, but soon spread to the right side of the mouth. 
A consultant neurologist found that she had right hemifacial spasm and mild right limb ataxia. Skull $X$-rays, EEG, and csf examination were said to be normal, and he diagnozed 'Dyssynergia cerebellaris progressiva'. Her condition remained unchanged until July 1971, when she developed an ache 'like tooth-ache', in the right lower jaw. This was easily controlled with mild analgesics, but in July 1972 (now aged 51) she began having momentary severe lancinating pains in the same region. There was no constant trigger spot, but the pain was precipitated by talking, eating, and jarring the head. Sometimes she had tingling at the angle of the mouth. Carbamazepin (tegretol) gave good relief at first, but when it began to lose its effect, she was admitted to hospital in November 1972.

On examination she had intermittent irregular attacks of twitching of the right face, and a mild right lower facial weakness. Taste was normal and there was no fifth nerve deficit. There was slight ataxia of the right limbs, but no nystagmus and no pyramidal signs. Plain X-rays were normal, but a brain scan showed a large midline posterior fossa uptake. Angiography showed an enormous angioma, supplied by the right superior cerebellar and posterior inferior cerebellar arteries, projecting from the midline to the right side of the posterior fossa. It was clearly inoperable, but the neuralgia was successfully relieved by injection of phenol in myodil into the right trigeminal sensory root. Two months later she remains free of pain, but is otherwise unchanged.

\section{Case 2}

In 1952, a 55-year-old salesman developed rightsided trigeminal neuralgia. The neuralgia affected the second and third divisions and was quite typical, with a remitting course and trigger spots. In 1955 he underwent fractional section of the right trigeminal sensory root by the extradural middle fossa approach. Pre-operatively no abnormal signs were present except for a very mild right upper and lower facial weakness, which was attributed to an old war wound in the upper part of the neck. He remained pain-free until July 1972 (now 75) when he complained that his original neuralgia had returned. It was noticed that he had intermittent twitching of the right side of the face, and it emerged that this had gradually appeared over the preceding 5 years, pari passu with right-sided deafness and tinnitus. On examination, he had in addition to the trigeminal sensory loss from his operation (which had not altered), the hemifacial spasms and the mild right facial weakness, a severe right nerve deafness. There were no pyramidal or cerebellar signs. A brain scan was normal, but tomograms of the internal auditory meati showed funnelling on the right side, suggestive of an acoustic neuroma. In view of the patient's age, and the fact that he was now also suffering from severe ischaemic heart disease and prostatic carcinoma, further investigations or exploration were not felt to be justified. Tegretol (carbamazepine) gave relief to the neuralgia, but had to be discontinued because of nausea and unsteadiness. The patient declined to

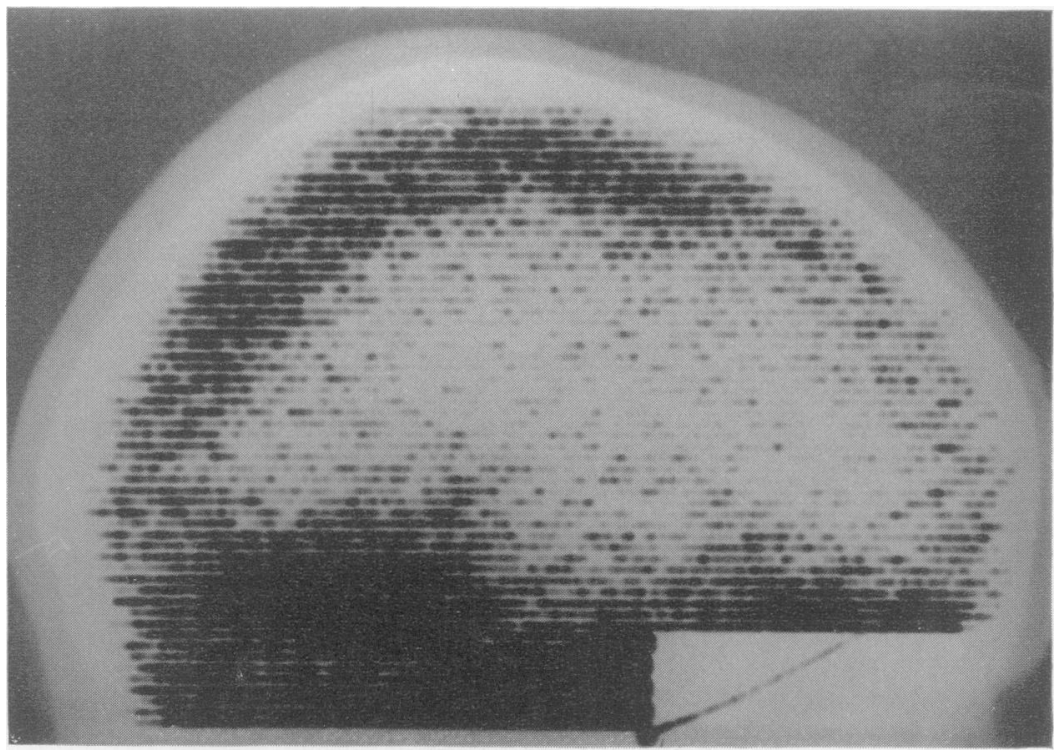

FIG. 1. Case 1: Brain scan showing increased uptake in the posterior fossa. 


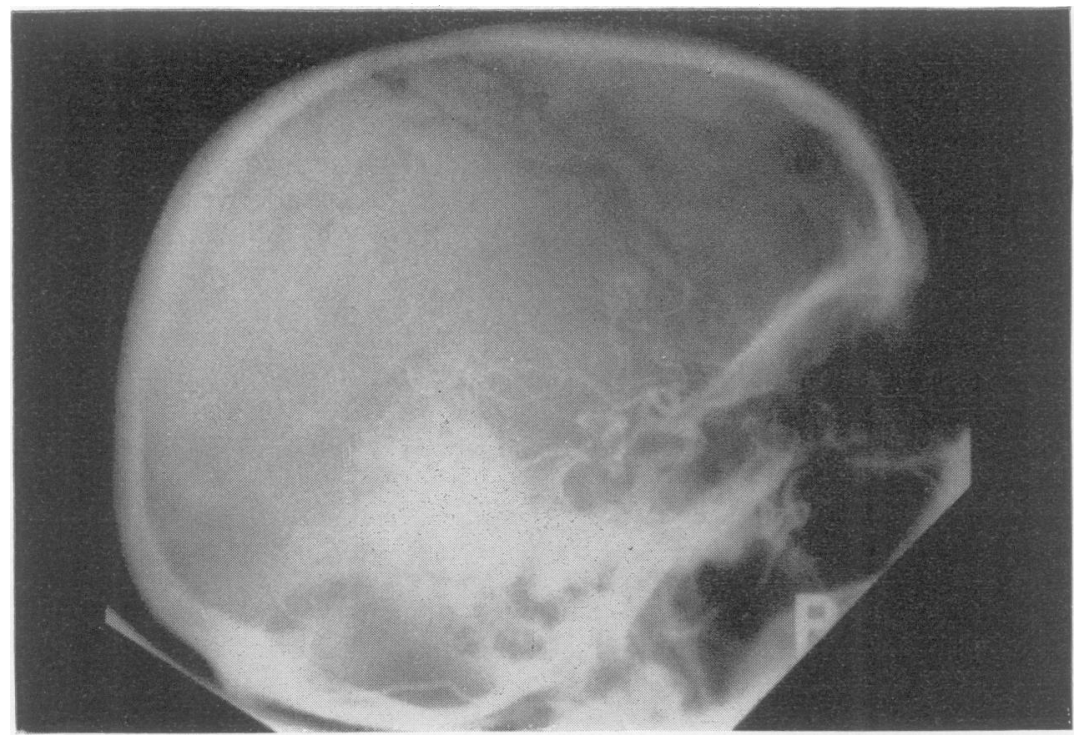

Fig. 2. Case 1. Vertebral angiogram showing posterior fossa angiona.

attend hospital for audiometry and caloric testing on account of his heart disease.

\section{Comment}

Although both trigeminal neuralgia and hemifacial spasm are conventionally regarded as idiopathic' disorders, otherwise typical instances of either disease may be found to be due to a cerebellopontine angle mass lesion. Opinions differ as to how often such a lesion is to be found. For trigeminal neuralgia, estimates vary from one in 500 cases (Penman, 1968), to $11 \%$ (Dandy, 1934). In hemifacial spasm such a lesion is held to be found only occasionally (Harris \& Wright, 1932), but in one series of nineteen patients who had posterior fossa explorations, a lesion impinging on the seventh nerve was said to be present in thirteen (Gardner \& Sava, 1962), although in six of these the lesion consisted of a slightly redundant normal artery.

The term 'tic convulsif' was first coined by Cushing (1920) to describe three cases of trigeminal neuralgia and hemifacial spasms occurring independently on the same side. Subsequent cases have been reported by Campbell \& Keedy (1947). Gardner (1970) collected eleven cases from the literature. Harris (1940) had seen fourteen cases in 'over 2500' cases of trigeminal neuralgia and commented 'what the relationship is between these two conditions I cannot even suggest'. Altogether, twenty-eight cases are reported in the literature. Of the twelve who were sufficiently investigated, a cerebellopontine angle lesion was found in eleven (six cirsoid aneurysms, two angiomas, and three cholesteatomas). The single exception, a case of Cushing's with negative postmortem findings, may have had facial pain of a nontrigeminal neuralgia type, as resection of the gasserian ganglion failed to relieve it. The details of the? two cases reported here suggest that in the residual sixteen cases, a causative lesion might eventually have been found had they been followed for long enough or been investigated in sufficient detail.

A lesion is more likely to give rise to neuralgia or spasm when it is slow growing. Of Dandy's series of 186 cerebellopontine angle tumours, trigeminal neuralgia or hemifacial spasm was commoner in the very slow-growing cholesteatomas (eleven out of sixteen) than in acoustic neuromas (twenty out of 160) (Gardner, 1970).

If it is accepted that the two constituent elements of tic convulsif are not merely coincidental, then a causative lesion involving both the fifth and seventh nerves could exist in only two possible sites: the brain stem or the cerebellopontine angle. The consensus of opinion is that the pathological basis for trigeminal neuralgia is located peripheral to the root entry zone of the brain stem (Kerr, 1970) and recently electron microscopy has been said to show changes in the gasserian ganglion and sensory root (Beaver, 1967). Hemifacial spasm is held to be due to a disorder of the lower motor neurone of the facial nerve, possibly in many cases from constriction within the facial canal (Zulch, 1970). As for the brain stem, it has been asserted that neither true trigeminal neuralgia (Kerr, 1970) nor true hemifacial 
spasm (Revilla, 1962) has ever been reported with a brain stem lesion involving neurones other than the most peripheral though such lesions may cause other types of trigeminal sensory and facial motor disturbance.

Recently, hemifacial spasm and trigeminal neuralgia have been linked in a single aetiological theory (Gardner, 1970). It is postulated that in both, shortcircuiting of impulses between adjacent peripheral nerve fibres gives rise to paroxysmal motor and sensory discharges. The approximation of the fibres permitting these 'sparkings' could be due either to chronic mild compression as from minor arterial anomalies or to the loss of insulating myelin from ageing or demyelinating disease. The co-existence of the two disorders as tic convulsif lends plausability to this theory.

\section{Acknowledgments}

I should like to thank Mr J. J. Maccabe and Mr P. H. Schurr for permission to report on cases treated under their care, and Professor C. D. Marsden, Professor of Neurology at the Institute of Psychiatry, for his helpful comments on this paper.

\section{References}

BeAVER, D.L. (1967) Electron microscopy of the Gasserian Ganglion in Trigeminal neuralgia. Journal of Neurosurgery, 26, 138.

Campbell, E.H. \& Keedy, C. (1947) Hemifacial spasm; note on aetiology in two cases. Journal of Neurosurgery, 4, 342 .

Cushing, H. (1920) Major Trigeminal Neuralgias and their surgical treatment. American Journal of Medical Science, $160,157$.

DANDY, W.E. (1934) Concerning causes of trigeminal neuralgia. American Journal of Surgery, 24, 447.

GARDNER, W.J. (1970) In: Trigeminal neuralgia. Georg Thieme, Stuttgart.

Gardner, W.J. \& SAva, G.A. (1962) Hemifacial spasm-a reversible pathophysiologic state. Journal of Neurosurgery, $19,240$.

HARRIS, W. (1940) An analysis of 1433 cases of paroxysmal trigeminal neuralgia. Brain, 63, 209.

HaRRIs, W. \& Wright, A.D. (1932) Treatment of clonic facial spasm. Lancet, i, 657.

KERR, F.W.L. (1970) In: Trigeminal neuralgia. Georg Thieme, Stuttgart.

Penman, J. (1968) Handbook of Clinical Neurology, Vol. 5, p. 312, Amsterdam.

ReVILlA, A.G. (1962) Journal of Neurosurgery, 19, 958.

Zulch, K.J. (1970) Handbook of Clinical Neurology, Vol. 8, p. 277, Amsterdam. 